\title{
LA CUESTIÓN SOCIAL Y ÉTICA DEL TRABAJO EN EL 40 ANIVERSARIO DE LABOREM EXERCENS
}

\section{The Social and Ethical Issue of Labor on the 40th Anniversary of Laborem Exercens}

\author{
Agustín Ortega Cabrera \\ Universidad Femenina del Sagrado Corazón \\ Lima - Perú \\ https://orcid.org/0000-0003-4323-3798 \\ agustinortegac@unife.edu.pe
}

\begin{abstract}
RESUMEN
Este artículo estudia e investiga la realidad sociohistórica y ética del trabajo, conmemorando el 40 aniversario de la encíclica Laborem exercens (LE), realizada por San Juan Pablo II. Pretende exponer así la actualidad de toda esta enseñanza social y moral de la fe e iglesia, con los Papas como Francisco, que continua y profundiza estas cuestiones sociales y éticas sobre el trabajo. Para ello, emplea la metodología propia de la teología y doctrina social de la iglesia (DSI), con su perspectiva interdisciplinar, analizando de forma interdisciplinar la realidad del trabajo y el estado de dicha cuestión, con estudios o autores significativos al respecto, en dialogo con las ciencias sociales o humanas y la filosofía, y con los movimientos sociales como el obrero.
\end{abstract}

\section{Palabras clave:}

Trabajo, doctrina social de la iglesia, moral, Laborem exercens, San Juan Pablo II, Francisco

\section{ABSTRACT}

This article studies and investigates the socio-historical and ethical reality of labor, commemorating the 40th anniversary of the encyclical Laborem exercens (LE), written by Saint John Paul II. In this way, it intends to expose the actuality of the social and moral teaching of the faith and the church, along with Popes like Francis, who continues to delve into these social and ethical questions about labor. To do this, it uses the methodology of the theology and social doctrine of the church (DSI), with its interdisciplinary perspective, analyzing in an interdisciplinary way the reality of labor and the state of said issue, with studies or significant authors in this regard, in dialogue with the social or human sciences and philosophy, and with social movements such as the labor movement.

\section{Keywords:}

Labor, social doctrine of the church, morality, Laborem exercens, Saint John Paul II, Francis 


\section{INTRODUCCIÓN}

El trabajo es una cuestión muy significativa, que ha sido estudiada por las ciencias sociales y la filosofía. Esta actividad social y económica tan relevante, asimismo, ha sido tratada por la DSI con los Papas (Sandoval, 2019). Tal como nos transmite San Juan Pablo II en su imprescindible encíclica al respecto, LE sobre el trabajo humano, u otros documentos sociales del magisterio en torno a estas cuestiones (Ibañez, 2002). "El trabajo humano es una clave, quizá la clave esencial, de toda la cuestión social, si tratamos de verla verdaderamente desde el punto de vista del bien del hombre. Y si la solución, o mejor, la solución gradual de la cuestión social, que se presenta de nuevo constantemente y se hace cada vez más compleja, debe buscarse en la dirección de «hacer la vida humana más humana», entonces la clave, que es el trabajo humano, adquiere una importancia fundamental y decisiva" (LE 3).

En este sentido, el trabajo, la vida de la persona trabajadora con su dignidad y derechos que efectúa realmente la justicia social (global) con los pobres de la tierra, es un elemento inherente de una auténtica ecología integral. Tal como nos transmite Francisco en Laudato si que remite a LE, valorándola como como una enseñanza que nos muestra una profunda sabiduría (LS 124-129). El trabajo es una realidad vital para cuidar y fecundar la creación, posibilitando que desarrolle todas sus potencialidades, capacidades y frutos de bien para toda la humanidad. En su reciente e imprescindible encíclica profética Fratelli tutti (FT), Francisco nos lo acaba de volver a recordar y subrayar, profundizando en estas cuestiones, para ir efectuando una actuación realmente ética, solidaria y efectivamente transformadora.
El Papa ratifica que el "gran tema es el trabajo. Lo verdaderamente popular porque promueve el bien del pueblo_- es asegurar a todos la posibilidad de hacer brotar las semillas que Dios ha puesto en cada uno, sus capacidades, su iniciativa, sus fuerzas. Esa es la mejor ayuda para un pobre, el mejor camino hacia una existencia digna. Por ello insisto en que «ayudar a los pobres con dinero debe ser siempre una solución provisoria para resolver urgencias. El gran objetivo debería ser siempre permitirles una vida digna a través del trabajo»... La política no puede renunciar al objetivo de lograr que la organización de una sociedad asegure a cada persona alguna manera de aportar sus capacidades y su esfuerzo. Porque «no existe peor pobreza que aquella que priva del trabajo y de la dignidad del trabajo». En una sociedad realmente desarrollada el trabajo es una dimensión irrenunciable de la vida social, ya que no sólo es un modo de ganarse el pan, sino también un cauce para el crecimiento personal, para establecer relaciones sanas, para expresarse a sí mismo, para compartir dones, para sentirse corresponsable en el perfeccionamiento del mundo, y en definitiva para vivir como pueblo" (FT 162).

Como vemos, ello permite un diálogo crítico, ético e interdisciplinar con otras filosofías o teorías (ciencias) sociales críticas, que han afrontado dicha cuestión de forma similar, con sus carencias o límites y errores, como las valora la DSI, junto a análisis interesantes y ciertos (Gasda, 2012). En esta línea, en Spe salvi (SS) Benedicto XVI afirma que "hacía falta el salto revolucionario. Karl Marx recogió esta llamada del momento y, con vigor de lenguaje y pensamiento, trató de encauzar este nuevo y, como él pensaba, definitivo gran paso de la historia hacia la salvación... Con precisión puntual, aunque de modo unilateral y parcial, Marx 
ha descrito la situación de su tiempo y ha ilustrado con gran capacidad analítica los caminos hacia la revolución... Su promesa, gracias a la agudeza de sus análisis y a la clara indicación de los instrumentos para el cambio radical, fascinó y fascina todavía hoy de nuevo...Como se observa hay puntos similares...Pero con su victoria se puso de manifiesto también el error fundamental de Marx. Él indicó con exactitud cómo lograr el cambio total de la situación. Pero no nos dijo cómo se debería proceder después..." (SS 20-21).

\section{El trabajo como causa de la pobreza y factor decisivo de la acción social en el desarrollo}

En esta DSI con los Papas como San Juan Pablo II y LE, se nos muestra como la desigualdad e injusticia del desempleo (paro) estructural y del trabajo basura e indecente: es la principal causa de la pobreza y del subdesarrollo de las personas, de los pueblos y de los pobres. Tal como actualmente visibilizan los estudios sociales, por ejemplo, sobre esa realidad injusta de los working poors, los trabajadores empobrecidos, ese grupo social del precariado, con un salario injusto, un trabajo basura e indecente (Rodríguez Guerra, 2013; Standing, 2013). Junto al negocio del paro para controlar el mundo del trabajo, mantener "a raya" a los trabajadores y aumentar las ganancias. Efectivamente, ya nos enseña San Juan Pablo II que "los «pobres» se encuentran bajo diversas formas; aparecen en diversos lugares y en diversos momentos; aparecen en muchos casos come resultado de la violación de la dignidad del trabajo humano: bien sea porque se limitan las posibilidades del trabajo — es decir por la plaga del desempleo-, bien porque se deprecian el trabajo y los derechos que fluyen del mismo, especialmente el derecho al justo salario, a la seguridad de la persona del trabajador y de su familia" (LE 8). Citando este texto de LE, Benedicto XVI constata como "al considerar los problemas del desarrollo, se ha de resaltar la relación entre pobreza y desocupación" (CV 63).

Por tanto, como seguiremos profundizando, hay que promover la justicia social y global, con el reparto de los bienes por medio del trabajo digno junto a un salario justo. Como continúa mostrando Francisco en LS, "en la actual realidad social mundial, más allá de los intereses limitados de las empresas y de una cuestionable racionalidad económica, es necesario que se siga buscando como prioridad el objetivo del acceso al trabajo por parte de todos. Estamos llamados al trabajo desde nuestra creación. No debe buscarse que el progreso tecnológico reemplace cada vez más el trabajo humano, con lo cual la humanidad se dañaría a sí misma. El trabajo es una necesidad, parte del sentido de la vida en esta tierra, camino de maduración, de desarrollo humano y de realización personal. En este sentido, ayudar a los pobres con dinero debe ser siempre una solución provisoria para resolver urgencias. El gran objetivo debería ser siempre permitirles una vida digna a través del trabajo. No debe buscarse que el progreso tecnológico reemplace cada vez más el trabajo humano, con lo cual la humanidad se dañaría a sí misma. El trabajo es una necesidad, parte del sentido de la vida en esta tierra, camino de maduración, de desarrollo humano y de realización personal. En este sentido, ayudar a los pobres con dinero debe ser siempre una solución provisoria para resolver urgencias. El gran objetivo debería ser siempre permitirles una vida digna a través del trabajo" (LS 127-128).

Y, de esta forma, no caer en el paternalismo asistencialista que hacen a 
las personas dependientes y dominadas, solo dando "ayudas" como (por ejemplo) bolsas de comida u otros recursos, sin transformar las causas del mal e injusticias. Tal como nos enseña el Concilio Vaticano II en Apostolicam actuositate (AA), se ha de "considerar, con la máxima delicadeza, la libertad y dignidad de la persona que recibe el auxilio; que no se manche la pureza de intención con ningún interés de la propia utilidad o por el deseo de dominar; se satisfaga ante todo a las exigencias de la justicia, y no se brinde como ofrenda de caridad lo que ya se debe por título de justicia; se quiten las causas de los males, no sólo los efectos, y se ordene el auxilio de forma que quienes lo reciben se vayan liberando poco a poco de la dependencia externa y se vayan bastando por sí mismos" (AA 8). Se trata pues, en forma ética, de no encubrir ni legitimar estas desigualdades e injusticias sociales y globales, como este mal acceso y reparto inequitativo del trabajo o un empleo basura e indecente. Dando a cambio, como un mecanismo injusto, únicamente un dinero en forma de renta o subsidio u otra ayuda como dichas bolsas de alimentos, para maquillar y mantener así estas desigualdades sociales e injusticias mundiales. Manipulando, de este modo, las conciencias. La ética junto a la fe e iglesia buscan esta solidaridad real y justicia social (global), tal como visibiliza la moral y su DSI.

En esta línea, en Evangelii gaudium (EG) Francisco nos sigue enseñando que "no hablamos sólo de asegurar a toda la comida, o un «decoroso sustento», sino de que tengan «prosperidad sin exceptuar bien alguno». Esto implica educación, acceso al cuidado de la salud y especialmente trabajo, porque en el trabajo libre, creativo, participativo y solidario, el ser humano expresa y acrecienta la dignidad de su vida. El salario justo permite el acceso adecuado a los demás bienes que están destinados al uso común. Los planes asistenciales, que atienden ciertas urgencias, sólo deberían pensarse como respuestas pasajeras. Mientras no se resuelvan radicalmente los problemas de los pobres, renunciando a la autonomía absoluta de los mercados y de la especulación financiera y atacando las causas estructurales de la inequidad, no se resolverán los problemas del mundo y en definitiva ningún problema. La inequidad es raíz de los males sociales..., ya no podemos confiar en las fuerzas ciegas y en la mano invisible del mercado. El crecimiento en equidad exige algo más que el crecimiento económico, aunque lo supone, requiere decisiones, programas, mecanismos y procesos específicamente orientados a una mejor distribución del ingreso, a una creación de fuentes de trabajo, a una promoción integral de los pobres que supere el mero asistencialismo" (EE 192, 202-204).

\section{El conflicto social del trabajo- capital y la opción por la justicia con los pobres}

Ya hemos apuntado y ahora ahondamos en ello, como analizan las ciencias y estudios sociales junto a la DSI con San Juan Pablo II en LE, este conflicto social entre clases o grupos hegemónicos poseedores del poder, del capital y la riqueza: que dominan, oprimen y empobrecen a las personas u otros colectivos, a los trabajadores, a los pueblos y a los pobres (Díaz Salazar, 2012; Kerbo, 2003). Realmente existen unas élites económicas, financieras, políticas, militares, culturales e ideológicas, tanto a nival local como internacional. Estas élites y grupos de poder imponen su hegemonía, causando y perpetuando toda esta desigualdad e injusticia en forma de explotación y esclavitud 
laboral, de pobreza y exclusión, de violencia estructural u otros conflictos sociales.

Se puede observar, como venimos señalando y resalta San Juan Pablo II, que "el problema del trabajo ha sido planteado en el contexto del gran conflicto, que en la época del desarrollo industrial y junto con éste se ha manifestado entre el «mundo del capital» y el «mundo del trabajo», es decir, entre el grupo restringido, pero muy influyente, de los empresarios, propietarios o poseedores de los medios de producción y la más vasta multitud de gente que no disponía de estos medios, y que participaba, en cambio, en el proceso productivo exclusivamente mediante el trabajo. Tal conflicto ha surgido por el hecho de que los trabajadores, ofreciendo sus fuerzas para el trabajo, las ponían a disposición del grupo de los empresarios, y que éste, guiado por el principio del máximo rendimiento, trataba de establecer el salario más bajo posible para el trabajo realizado por los obreros. A esto hay que añadir también otros elementos de explotación, unidos con la falta de seguridad en el trabajo y también de garantías sobre las condiciones de salud y de vida de los obreros y de sus familias....Ante la realidad actual, en cuya estructura se encuentran profundamente insertos tantos conflictos, causados por el hombre, y en la que los medios técnicos - fruto del trabajo humanojuegan un papel primordial (piénsese aquí en la perspectiva de un cataclismo mundial en la eventualidad de una guerra nuclear con posibilidades destructoras casi inimaginables)..." (LE 11-12).

El Papa en LE visibiliza pues, claramente, dicho conflicto social del capital contra el trabajo, como el capitalismo oprime y viola la vida digna de los trabajadores, de las personas y los pobres (Alcaide,
2007; Gasda, 2017). Así nos lo transmite Francisco en todo su magisterio (EG 226230), subrayando la prioridad de la unidad solidaria y la justicia. Frente a todo este conflicto que impone la desigualdad e injusticia, como acontece en el mundo del trabajo (LS 127). Enfatizando que el actual sistema económico mata y excluye, genera inequidad e idolatría del dinero, ese ídolo de la riqueza-ser rico, dicta la globalización de la indiferencia y la cultura del descarte, que niega la vida de las personas más débiles o vulnerables (FT 18-19).

Al respecto de esta cuestión, en Centesimus annus (CA) San Juan Pablo II nos sigue enseñando que la fe e iglesia con su DSI "ciertamente, no pretende condenar todas y cada una de las formas de conflictividad social. La Iglesia sabe muy bien que, a lo largo de la historia, surgen inevitablemente los conflictos de intereses entre diversos grupos sociales y que frente a ellos el cristiano no pocas veces debe pronunciarse con coherencia y decisión. La iglesia ha reconocido claramente el papel positivo del conflicto cuando se configura como «lucha por la justicia social». Lo que se condena en la lucha de clases es la idea de un conflicto que no está limitado por consideraciones de carácter ético o jurídico, que se niega a respetar la dignidad de la persona en el otro y por tanto en sí mismo, que excluye, en definitiva, un acuerdo razonable y persigue no ya el bien general de la sociedad, sino más bien un interés de parte que suplanta al bien común y aspira a destruir lo que se le opone. Se trata, en una palabra, de presentar de nuevo - en el terreno de la confrontación interna entre los grupos sociales - la doctrina de la «guerra total», que el militarismo y el imperialismo de aquella época imponían en el ámbito de las relaciones internacionales" (CA 14). 
Aún con términos más vigorosos y rotundos siguiendo al Concilio Vaticano II (GS 27), explícitamente en Evangelium vitae (EV) con su bioética global que se une inseparablemente a la ecología social e integral o en Pastores gregis (PG), San Juan Pablo II analiza todo esta conflictividad e injusticia social. Visibilizando la actual guerra de los poderosos y ricos contra los débiles y los pobres, mediante una estructura de pecado que domina y destruye con su cultura de la muerte (EV 3-12); donde los ricos están cada vez más enriquecidos, a costa de que pobres sean más empobrecidos, como siguen afirmando San Pablo VI y San Juan Pablo II (Puebla, III, 4). "Hoy más que ayer, la guerra de los poderosos contra los débiles ha abierto profundas divisiones entre ricos y pobres. iLos pobres son legión! En el seno de un sistema económico injusto, con disonancias estructurales muy fuertes, la situación de los marginados se agrava de día en día. En la actualidad hay hambre en muchas partes de la tierra, mientras en otras hay opulencia. Las víctimas de estas dramáticas desigualdades son sobre todo los pobres, los jóvenes, los refugiados. En muchos lugares, también la mujer es envilecida en su dignidad de persona, víctima de una cultura hedonista y materialista" (PG 67).

De esta forma, la fe e iglesia con la DSI no oculta ni permanece neutral ante el hecho del conflicto social con su lucha de clases, sino que lo asume solidariamente poniéndose de parte de las víctimas, de los pobres, de los trabadores oprimidos y empobrecidos. Promoviendo así, sin odio ni agresiones, esta lucha pacífica y no violenta por la justicia social y global con los pobres, por el bien común más universal y la dignidad de toda persona trabajadora. En esta dirección, como refiere San Juan Pablo II en los textos citados, ya en
Quadragesimo anno (QA) Pío XI nos muestra el conflicto entre las clases sociales y la injusticia inherente del capitalismo con su ideología liberal. "En efecto, cuando la lucha de clases se abstiene de los actos de violencia y del odio recíproco, se transforma poco a poco en una discusión honesta, fundada en la búsqueda de la justicia" (OA 213). La DSI con los Papa como San Juan Pablo II en LE, por ello, reconocen, valoran y alaban todo este inherente sentido solidario, social y moral de los movimientos históricos de los trabajadores y los pobres. Tal como es el denominando movimiento obrero, con su cultura de la solidaridad y la lucha por la justicia, ante el mal e injusticia del capitalismo que los empobrece (Peláez, 2009).

Efectivamente, todo este conflicto e injusticia social del capital sobre el trabajo "ha dado origen a una justa reacción social, ha hecho surgir y casi irrumpir un gran impulso de solidaridad entre los hombres del trabajo y, ante todo, entre los trabajadores de la industria. La llamada a la solidaridad y a la acción común, lanzada a los hombres del trabajo - sobre todo a los del trabajo sectorial, monótono, despersonalizador en los complejos industriales, cuando la máquina tiende a dominar sobre el hombre - tenía un importante valor y su elocuencia desde el punto de vista de la ética social. Era la reacción contra la degradación del hombre como sujeto del trabajo, y contra la inaudita y concomitante explotación en el campo de las ganancias, de las condiciones de trabajo y de previdencia hacia la persona del trabajador. Semejante reacción ha reunido al mundo obrero en una comunidad caracterizada por una gran solidaridad. Tras las huellas de la Encíclica Rerum novarum y de muchos documentos sucesivos del Magisterio de 
la Iglesia se debe reconocer francamente que fue justificada, desde la óptica de la moral social, la reacción contra el sistema de injusticia y de daño, que pedía venganza al cielo, y que pesaba sobre el hombre del trabajo en aquel período de rápida industrialización" (LE 8).

Y es que, en esta línea, como enfatiza la DSI no habrá paz ni se acabará con estos conflictos, guerras y violencias (FT 127): si no existe ese otro mundo posible más justo y fraterno, con trabajo digno, tierra, y techo para todos. Como está acentuando Francisco. "este es el verdadero camino de la paz, y no la estrategia carente de sentido y corta de miras de sembrar temor y desconfianza ante amenazas externas. Porque la paz real y duradera sólo es posible «desde una ética global de solidaridad y cooperación al servicio de un futuro plasmado por la interdependencia y la corresponsabilidad entre toda la familia humana»" (FT 127). Cuando no existe el bien común con las condiciones sociales e históricas (de todo tipo) que aseguren el desarrollo integral, garantizando los derechos humanos como es un trabajo decente, entonces se va originado el caldo de cultivo que alimentan los conflictos sociales; con inseguridad ciudadana, delincuencia, guerras y violencia de todo tipo (Redorta, 2011).

En este sentido, continuando con este legado de la DSI y San Pablo VI, iSan Juan Pablo II sigue clamando el "nunca más la guerra!». iNo, nunca más la guerra!, que destruye la vida de los inocentes, que enseña a matar y trastorna igualmente la vida de los que matan, que deja tras de sí una secuela de rencores y odios, y hace más difícil la justa solución de los mismos problemas que la han provocado... No hay que olvidar tampoco que en la raíz de la guerra hay, en general, reales y graves razones: injusticias sufridas, frustraciones de legítimas aspiraciones, miseria o explotación de grandes masas humanas desesperadas, las cuales no ven la posibilidad objetiva de mejorar sus condiciones por las vías de la paz. Por eso, el otro nombre de la paz es el desarrollo..." (CA 52).

\section{Claves, principios y valores para la ética social del trabajo}

\section{El trabajo sobre el capital}

En esta trascendencia y dignidad del trabajo, para los Papas como San Juan Pablo II en LE y la DSI, la clave es el trabajo subjetivo, el trabajo vivo que realiza el ser humano. La persona expresa y realiza una dimensión constitutiva de su vida con el trabajo. Por tanto, el sujeto y la persona del trabajo está antes que el trabajo objetivo, que la productividad o eficacia, está por encima del capital (LE 6). El trabajador con su vida digna es más importante que el producto del trabajo y la mercancía fabricada, que no pueden convertirse en fetiches e ídolos, falsos dioses, a los que sacrificar la existencia de las personas y la dignidad de los trabajadores (Segovia, 2013). "Se debe ante todo recordar un principio enseñado siempre por la Iglesia. Es el principio de la prioridad del «trabajo» frente al «capital». Este principio se refiere directamente al proceso mismo de producción. Respecto al cual, el trabajo es siempre una causa eficiente primaria. Mientras el «capital», siendo el conjunto de los medios de producción, es sólo un instrumento o la causa instrumental... Conviene subrayar y poner de relieve la primacía de la persona en el proceso de producción, la primacía del ser humano respecto de las cosas" (LE 12).

Como se observa y sigue enseñando San Juan Pablo II junto a la DSI, se reafirma 
así todo el humanismo y principio del trabajo que tiene la prioridad sobre el capital (LE 12), que está antes que el beneficio, la ganancia, es primero que la productividad y la competitividad. En la actualidad, como crítica y denuncia Francisco, se van imponiendo el fetichismo del dinero, la dictadura de la economía con el mercado-capital como idolatrías que niegan al ser humano y a Dios (EG 55). Por tanto, hay que defender a la persona que es el centro, sujeto y protagonista gestor de dicha realidad laboral, social e histórica.

"El trabajo está «en función del ser humano»y no el ser humano en «en función del trabajo»... Es el metro de la dignidad del sujeto mismo del trabajo" (LE 6). Más, como ha sucedido en dicha realidad social e histórica, el capitalismo pervierte este justo orden de valores, ya que niega a la persona trabajadora como "sujeto eficiente y su verdadero artíficecreador... En donde es tratado, a la par de todo el complejo de los medios materiales de producción, como un instrumento y no según la verdadera dignidad de su trabajo; o sea como sujeto y autor y, por consiguiente, como verdadero fin de todo el proceso productivo" (LE 7).

De ahí, frente a la entraña perversa del capitalismo, que haya que reafirmar el trabajo, la dignidad y protagonismo del ser humano trabajador, sobre el capital (Gasda, 2017). Este humanismo integral de la DSI con Juan Pablo II (LE 15), en sintonía con el personalismo, subraya pues el valor y principio fundamental del trabajo, la vida y dignidad de la persona trabajadora, que se sobrepone al capital. En contra de la esencia inmoral del capitalismo, que antepone el capital al trabajo, que niega la vida y dignidad del trabajador, que va en contra del ser humano y sus derechos como es un trabajo decente con un salario junto (Alburquerque, 2006). Y que genera el conflicto social ya expuesto en forma de dominación, desigualdad, injusticia y violencia estructural del capital sobre el trabajo y los pobres, explotando y empobreciendo a los trabajadores, a las personas y a sus familias.

Como de forma magistral analiza y enseña todo ello San Juan Pablo II, "en todos los casos de este género, en cada situación social de este tipo se da una confusión, e incluso una inversión del orden establecido desde el comienzo con las palabras del libro del Génesis: el hombre es considerado como un instrumento de producción, mientras él, —él solo, independientemente del trabajo que realiza- debería ser tratado como sujeto eficiente y su verdadero artífice y creador. Precisamente tal inversión de orden, prescindiendo del programa y de la denominación según la cual se realiza, merecería el nombre de «capitalismo» en el sentido indicado más adelante con mayor amplitud" (LE 7). Tanto el capitalismo con su liberalismo económico, como esa mala respuesta que es el totalitarismo del comunismo colectivista o colectivismo (ese capitalismo de estado), tienen la misma raíz perversa: el error del economismo, el materialismo economicista; lo que niega este valor y principio de la primacía de la persona sobre las cosas, del trabajo del ser humano sobre el capital y su conjunto de medios de producción (LE 13).

La DSI con el Papa Juan Pablo II, pues, se posicionan en contra de los males e injusticias del capital, del liberalismo economicista y del capitalismo o del totalitarismo del comunismo colectivista (colectivismo) que, como hemos apuntado y afirma dicho Papa, en realidad no es más que un capitalismo de estado (CA 35). La DSI y San Juan Pablo II, como afirma en Sollicitudo rei socialis (SRS), es crítica con 
estos dos sistemas e ideologías, con el capitalismo y el comunismo colectivista (SRS 21). Al igual que Benedicto XVI, mostrando que su "promesa ideológica se ha demostrado que es falsa" (Aparecida 4); ya que la libertad moral es negada e impedida por el colectivismo e igualmente, o aún peor, es tergiversada y manipulada por el neoliberalismo. En el capitalismo, el ser libre se subvierte en un individualismo posesivo e insolidario que, con su relativismo y hedonismo, niega la ética con los valores esenciales u objetivos como es la dignidad de la persona, la justicia social y el bien común. Convirtiéndose así en una auténtica corrupción de la verdadera libertad (CA 33, 35, 42).

Frente al capitalismo, como seguiremos desarrollando, la DSI transmite que el destino universal de los bienes está por encima de la propiedad privada, que es para todos y tiene un carácter social. Tal como nos enseña el Vaticano II (GS 69) y Juan Pablo II (LE 14). De ahí que una clave esencial de la cuestión social y del trabajo es que se garantice un salario digno, un sueldo justo para las personas trabajadoras y sus familias (LE 19). Por eso hay que que darle al trabajo, con la realización y dignidad del trabajador, la prioridad sobre el capital, el beneficio y los medios de producción (LE 13). Estos medios de producción con la empresa deben ser socializados, todos los trabajadores deben ser autores, gestores y dueños de la empresa con los medios de producción en una economía social y cooperativa (LE 14-15).

"Justo, es decir, conforme a la esencia misma del problema; justo, es decir, intrínsecamente verdadero y a su vez moralmente legítimo, puede ser aquel sistema de trabajo que en su raíz supera la antinomia entre trabajo y el capital, tratando de estructurarse según el principio expuesto más arriba de la sustancial y efectiva prioridad del trabajo, de la subjetividad del trabajo humano y de su participación eficiente en todo el proceso de producción, y esto independientemente de la naturaleza de las prestaciones realizadas por el trabajador" (LE 13).

De ahí que, como sigue enseñando San Juan Pablo II, se puede hablar justamente de lucha contra este sistema económico capitalista. Lo moral es luchar contra el capitalismo, porque permanentemente utiliza como método el predominio absoluto del capital, la posesión de los medios de producción y de la tierra en contra de la libre subjetividad del trabajo de la persona (CA 35). Y aunque el capitalismo (hoy global) es el sistema e ideología que más domina actualmente, San Juan Pablo II no lo acepta como vencedor ni como alternativa (CA 35), debido a que es inhumano e impone las cosas sobre las personas, marginando a los pobres y pueblos del sur empobrecido (CA 34).

\section{Destino universal de los bienes y salario justo antes que la propiedad}

Es por todo ello como ya enunciamos anteriormente, en contra de estas ideologías y sistemas economicistas como el capitalismo o el comunismo colectivista, que la fe e iglesia defiende la propiedad para toda la humanidad. Y no sólo para unos pocos ricos, lo cual va en contra del principio del destino universal de los bienes (LE 14; Sorge, 2017). Frente a la naturaleza injusta e inmoral del capitalismo, lo primero no es la propiedad privada, que no es un dogma ni un derecho absoluto e intocable. Lo principal y clave es este destino universal 
de los bienes, que es "el primer principio de todo el ordenamiento ético-social" (LE 19). Recogiendo toda esta enseñanza de la DSI y San Juan Pablo II con LE, el Papa Francisco ha remarcado este principio de la primacía del destino universal de los bienes, que hace real la justicia social y global con la equidad en la distribución de los recursos, sobre la propiedad (LS 93-95).

Francisco sigue transmitiendo el principio y derecho natural del destino universal de los bienes, que tiene la prioridad sobre el derecho secundario de la propiedad privada (FT 118-120), que no se puede sacralizar ni idolatrar. "Vuelvo a hacer mías y a proponer a todos unas palabras de san Juan Pablo II cuya contundencia quizás no ha sido advertida: «Dios ha dado la tierra a todo el género humano para que ella sustente a todos sus habitantes, sin excluir a nadie ni privilegiar a ninguno». En esta línea recuerdo que «la tradición cristiana nunca reconoció como absoluto o intocable el derecho a la propiedad privada y subrayó la función social de cualquier forma de propiedad privada». El principio del uso común de los bienes creados para todos es el «primer principio de todo el ordenamiento éticosocial», es un derecho natural, originario y prioritario" (FT 120).

La propiedad tiene pues un destino común, universal y grava solidariamente sobre ella una función (regulación) de carácter social. Así nos transmite todo ello los Santos Padres con el Vaticano II (GS 69), la DSI con San Pablo VI en Populorum progressio (PP 23) y San Juan Pablo II (LE 14). Se trata así de promover el principio y derecho natural, que conforma a la economía ética, como es este destino universal de los bienes, unido de suyo a la justicia social y global con este reparto equitativo mundial de los recursos, que tiene la prioridad sobre el derecho secundario de la propiedad privada. Tal como está subrayando actualmente Francisco (FT 118-120), en continuidad con toda la tradición de la iglesia y sus doctores como Santo Tomás de Aquino (Summa theologica II-II, 66-7; Tornielli y Galeazzi, 2015). De esta forma, se subraya que la propiedad no es un absoluto sagrado e intocable, sino que tiene un inherente destino social y universal, gravando sobre ella esta misión (control) moral de solidaridad global, para este reparto justo y mundial de los bienes.

En este sentido de dicho principio vital del destino universal de los bienes, hay que asegurar una clave de la ética social para esta justa distribución de los recursos, como es la justa remuneración (salario justo) por el trabajo realizado. "El salario, es decir, la remuneración del trabajo, sigue siendo una vía concreta, a través de la cual la gran mayoría de los hombres puede acceder a los bienes que están destinados al uso común: tanto los bienes de la naturaleza como los que son fruto de la producción. Los unos y los otros se hacen accesibles al hombre del trabajo gracias al salario que recibe como remuneración por su trabajo. No existe otro modo mejor para cumplir la justicia en las relaciones trabajador-empresario que el constituido, precisamente, por la remuneración del trabajo. El salario justo se convierte así en la verificación concreta de la justicia de todo el sistema socioeconómico, de su justo funcionamiento.... Es la verificación clave" (LE 9).

Debe ser un salario justo para el trabajador y su familia, que cubra todas sus necesidades y posibilite sus capacidades de todo tipo, garantizando el desarrollo humano e integral. Promover la vida y la familia, entonces, requiere constitutivamente esta lucha solidaria por 
la justicia en la realidad social e histórica del trabajo. Y es que las desigualdades e injusticias, que van en contra del trabajo digno y del salario justo, "afectan sobre todo a la familia. Una justa remuneración por el trabajo de la persona adulta que tiene responsabilidades de familia es la que sea suficiente para fundar y mantener dignamente una familia y asegurar su futuro. Tal remuneración puede hacerse bien sea mediante el llamado salario familiar -es decir, un salario único dado al cabeza de familia por su trabajo y que sea suficiente para las necesidades de la familia sin necesidad de hacer asumir a la esposa un trabajo retribuido fuera de casa- bien sea mediante otras medidas sociales, como subsidios familiares o ayudas a la madre que se dedica exclusivamente a la familia, ayudas que deben corresponder a las necesidades efectivas, es decir, al número de personas a su cargo durante todo el tiempo en que no estén en condiciones de asumirse dignamente la responsabilidad de la propia vida" (LE 9)

\section{Socialización de los medios de producción como clave de la vida económica y empresarial}

Desde este punto de vista, en consideración del trabajo humano y del acceso común a los bienes destinados a los seres humanos, es legítima y justa la clave que debe guiar la vida empresarial y económica: la socialización de los medios de producción (LE 13). La fe e iglesia defiende así una economía social y cooperativa, con la copropiedad de los medios del trabajo y de la empresa, la participación de las personas trabajadoras en la gestión y los beneficios empresariales, el llamado «accionariado» del trabajo, etc. (González-Carvajal, 2010). Es la socialización que asegura la subjetividad de la sociedad. Es decir, cuando todo ser humano, basándose en su propio trabajo, tenga pleno título a considerarse al mismo tiempo «copropietario» de esa especie de gran taller de trabajo en el que se compromete con todos...Se trata del argumento (personalista», con el principio de la prioridad del trabajo respecto al capital, como postulado que pertenece al orden de la moral social. Por medio de la socialización de los medios de producción, se hace posible que el ser humano pueda conservar la conciencia de trabajar en «algo propio» (LE 14-15).

En realidad, pues, el capital como la propiedad y los medios de producción "no pueden ser poseídos contra el trabajo, no pueden ser ni siquiera poseídos para poseer. El único título legítimo para su posesión - y esto ya sea en la forma de la propiedad privada, ya sea en la de la propiedad pública o colectiva- es que sirvan al trabajo; consiguientemente que, sirviendo al trabajo, hagan posible la realización del primer principio de aquel orden: el destino universal de los bienes y el derecho a su uso común" (LE 13). Y es que, en oposición al paternalismo asistencialista, en relación imprescindible con la transformación de las causas estructurales de la pobreza, hay que asumir esta cuestión solidaria y social central que es el trabajo (FT 116, 162). La economía y la empresa deben servir "claramente, al desarrollo de las demás personas y a la superación de la miseria, especialmente a través de la creación de fuentes de trabajo diversificadas" (FT 123; Cortina, 2003).

Frente a la especulación financiera, que especula con la vida y los bienes como son los alimentos (FT 189), provocando el holocausto del hambre y la pobreza. En contra del mal (pecado) tan grave de la usura con esas divisas, créditos e intereses: especulativos, abusivos, usureros e injustos que ha provocado, 
entre otros males, la deuda externa que empobrece a los pueblos (SRS 43). De ahí, nos sigue enseñando San Juan Pablo II, que los medios de producción con la propiedad "resulta ilegítima cuando no es valorada o sirve para impedir el trabajo de los demás u obtener unas ganancias, que no son fruto de la expansión global del trabajo y de la fecundidad social. Sino más bien de la explotación ilícita, de la especulación y de la ruptura de la solidaridad en el mundo laboral. Este tipo de propiedad no tiene ninguna justificación y constituye un abuso ante Dios y los hombres" (CA 43).

\section{Las organizaciones de los trabadores y el sindicalismo}

Ya señalamos como la DSI con San Juan Pablo II (LE 8, 11) muestra su reconocimiento y valoración a esa profunda corriente de solidaridad que es el movimiento obrero. Efectivamente, la fe e iglesia promueve e impulsa esas organizaciones sociales de trabajadores y sindicales que, de forma solidaria, luchan éticamente por la justicia. Frente a todo este conflicto social que causa el capitalismo, explotando injustamente a los trabajadores u obreros. "Para realizar la justicia social en las diversas partes del mundo, en los distintos países, y en las relaciones entre ellos, son siempre necesarios nuevos movimientos de solidaridad de las personas del trabajo y de solidaridad con los seres humanos del trabajo. Esta solidaridad debe estar siempre presente allí donde lo requiere la degradación social del sujeto del trabajo, la explotación de las personas trabajadoras y las crecientes zonas de miseria e incluso de hambre" (LE 8).

Desde la DSI y los Papas como San Juan Pablo II o Benedicto XVI, se propicia un diálogo crítico y compromiso común por la justicia en el trabajo, por la dignidad y ética liberadora con los pobres de la tierra. La Iglesia con los Papas valoran todo lo bueno y solidario del movimiento obrero u organizaciones de los trabajadores, como son los sindicatos, en la promoción y liberación integral de los pobres, de la dignidad de los trabajadores que son explotados y empobrecidos (Díaz Salazar, 2001). Sobre la base de todos los derechos sociolaborales, "junto con la necesidad de asegurarlos por parte de los mismos trabajadores, brota aún otro derecho, es decir, el derecho a asociarse; esto es, a formar asociaciones o uniones que tengan como finalidad la defensa de los intereses vitales de los hombres empleados en las diversas profesiones. Estas uniones llevan el nombre de sindicatos... Son un exponente de la lucha por la justicia social, por los justos derechos de los hombres del trabajo según las distintas profesiones" (LE 20).

El Papa Francisco asimismo alienta a estos movimientos solidarios y populares (MP) de trabajadores, campesinos, indígenas...Esos MP que son artífices y sujetos de la transformación social e histórica, para ir logrando el bien común más universal y la justicia socioambiental global (ecología integral) junto a las denominadas $3 \mathrm{~T}$, tierra, techo y trabajo para todos. Por ello, enseña Benedicto XVI que "es oportuno hacer un llamamiento a las organizaciones sindicales de los trabajadores, desde siempre alentadas y sostenidas por la Iglesia, ante la urgente exigencia de abrirse a las nuevas perspectivas que surgen en el ámbito laboral. Las organizaciones sindicales están llamadas a hacerse cargo de los nuevos problemas de nuestra sociedad... El contexto global en el que se desarrolla el trabajo requiere igualmente que las organizaciones sindicales nacionales, ceñidas sobre todo a la defensa de los intereses de sus afiliados, vuelvan su mirada también 
hacia los no afiliados y, en particular, hacia los trabajadores de los países en vía de desarrollo, donde tantas veces se violan los derechos sociales. La defensa de estos trabajadores, promovida también mediante iniciativas apropiadas en favor de los países de origen, permitirá a las organizaciones sindicales poner de relieve las auténticas razones éticas y culturales que las han consentido ser, en contextos sociales y laborales diversos, un factor decisivo para el desarrollo" (CV 64).

Es necesario así ejercer la crítica a los falsos nacionalismos, populismos, corporativismos y elitismos. Tanto los supuestos "progresismos" e izquierdas, así sea el comunismo colectivista (colectivismo), o de centro-derechas como son el neoliberalismo y el capitalismo (FT 155-157, 165). Francisco denuncia proféticamente y se opone a estos nacionalismos populistas, monopolios y totalitarismos, falsos dioses, del estado y mercado que tienen sus límites, que oprimen y empobrecen (FT 168 169). Por tanto, son imprescindibles autoridades e instituciones mundiales, $\mathrm{u}$ organizaciones internacionales como deben ser los sindicatos, que conjuntamente controlen ética y políticamente al mercado, que regulen la economía, a esta globalización del capital y la guerra. Y, en otra dirección, se fomente la civilización del amor fraterno, la mundialización de la paz y la solidaridad (FT 173-174). Tal como nos muestra la DSI con los Papas, por ejemplo, Benedicto XVI (CV 67).

Francisco visibiliza como "los últimos en general «practican esa solidaridad tan especial que existe entre los que sufren, entre los pobres, y que nuestra civilización parece haber olvidado, o al menos tiene muchas ganas de olvidar. Solidaridad es una palabra que no cae bien siempre, yo diría que algunas veces la hemos transformado en una mala palabra, no se puede decir; pero es una palabra que expresa mucho más que algunos actos de generosidad esporádicos. Es pensar y actuar en términos de comunidad, de prioridad de la vida de todos sobre la apropiación de los bienes por parte de algunos. También es luchar contra las causas estructurales de la pobreza, la desigualdad, la falta de trabajo, de tierra y de vivienda, la negación de los derechos sociales y laborales. Es enfrentar los destructores efectos del Imperio del dinero. [...] La solidaridad, entendida en su sentido más hondo, es un modo de hacer historia y eso es lo que hacen los movimientos populares»" (FT 116).

\section{Espiritualidad y teología del trabajo}

\section{Antropología teológica y creación}

Este pensamiento y la DSI nos presenta la actividad del trabajo como creación, a la persona trabajadora como creadora. Y que, en la dimensión teológica de la fe, colabora con el Dios Creador que en su amor gratuito ha creado todo el cosmos, el mundo y la tierra (LE 4). Es toda una ética, espiritualidad y teología del trabajo como ya nos mostrara la obra clásica de Chenu (Franco, 2007). "En la palabra de la divina Revelación está inscrita muy profundamente esta verdad fundamental, que el ser humano, creado a imagen de Dios, mediante su trabajo participa en la obra del Creador. Y según la medida de sus propias posibilidades, en cierto sentido, continúa desarrollándola y la completa... Esta descripción de la creación, que encontramos ya en el primer capítulo del libro del Génesis es, a su vez, en cierto sentido el primer «evangelio del trabajo». Ella demuestra, en efecto, en qué consiste su dignidad; enseña que la persona, trabajando, debe 
imitar a Dios, su Creador, porque lleva consigo —él solo- el elemento singular de la semejanza con Él. El ser humano tiene que imitar a Dios tanto trabajando como descansando, dado que Dios mismo ha querido presentarle la propia obra creadora bajo la forma del trabajo y del reposo..." (LE 25).

De esta forma, lo más importante es el trabajo subjetivo, el sujeto del trabajo que es la persona y que con su actividad laboral: crea, transforma y renueva la realidad e historia; a la vez que se realiza y desarrolla como ser humano en dicho trabajo (LE 6). Como nos muestra el Evangelio de Jesús (Mc 2, 27-28), nada ni nadie, ninguna realidad por más sagrada que se crea (ya sea la economía o el dinero-riqueza), puede ir en contra de la vida y dignidad del ser humano como es el trabajador. Como nos transmitía ya San Pablo VI, "creado a imagen suya, «la persona debe cooperar con el Creador en la perfección de la creación y marcar, a su vez, la tierra con el carácter espiritual que él mismo ha recibido». Dios, que ha dotado a la persona de inteligencia, le ha dado también el modo de acabar de alguna manera su obra; ya sea el artista o artesano, patrono, obrero o campesino, todo ser humano trabajador es un creador" (PP 25).

Desde la antropología bíblica y la teología de la creación (Ruíz de la Peña, 2012), como se observa, en esta DSI se visibiliza al ser humano con su actividad del trabajo, que crea y transforma la realidad. La persona que trabaja se manifiesta como colaboradora en la creación, como co-creadora en su trabajo y actividad transformadora, con el Dios Creador (Ruíz de la Peña, 2011). "El hombre es la imagen de Dios, entre otros motivos por el mandato recibido de su Creador... En la realización de este mandato, el hombre, todo ser humano, refleja la acción misma del Creador del universo" (LE 4). Se puede ver así la trascendencia e importancia que adquiere el trabajo en la fe bíblica-católica, como estudia esta antropología teológica. Ya que "en la palabra de la divina Revelación está inscrita muy profundamente esta verdad fundamental, que el hombre, creado a imagen de Dios, mediante su trabajo participa en la obra del Creador, y según la medida de sus propias posibilidades, en cierto sentido, continúa desarrollándola y la completa, avanzando cada vez más en el descubrimiento de los recursos y de los valores encerrados en todo lo creado" (LE 25).

\section{El Evangelio del trabajo y el Cristo obrero con su pascua}

Más propiamente en la plenitud de la Revelación cristiana-católica, el Dios encarnado en Jesús nace y vive en una familia trabajadora, humilde y pobre. El propio Cristo es un obrero que con su vida, enseñanza y actividad por el Reino de Dios con su justicia hasta la cruz: asume solidariamente el esfuerzo y sacrificio del trabajo. Mostrándonos así esta santidad salvadora del amor que se entrega, para toda esta actividad transformadora por el bien y la vida de los demás, que culmina en la resurrección y trascendencia eterna (LE 26-27). El Dios que se nos revela en Jesús de Nazaret, con su vida unida a su actividad, santifica el trabajo y todo el mundo social e histórico en el amor liberador, como nos comunica el mismo Vaticano II (GS 22). Y ello junto a San José obrero con María, la sagrada familia de Nazaret pobre y trabajadora, modelo de familia fraterna y obrera en la solidaridad. Todo un paradigma de este movimiento solidario y obrero, por esto, de la iglesia misma que es sacramento del Reino de Dios y su justicia (Díaz Salazar, 1998). 
Al respecto, San Juan Pablo II enseña que "uno de los contenidos más importantes de la Nueva Evangelización está constituido por el anuncio del Evangelio del Trabajo, que he presentado en mi encíclica LE. Y que, en las condiciones actuales, se ha vuelto especialmente necesario. Ello supone una intensa y dinámica pastoral de los trabajadores, tan necesaria hoy, como en el pasado, respecto del cual, bajo algunos aspectos, se ha vuelto todavía más difícil. La Iglesia tiene que buscar siempre nuevas formas y nuevos métodos, sin ceder al desaliento». (Alocución, 15-01- 1993).

Es el anuncio del Dios de la vida, de los obreros y de los pobres, que nos regala la salvación con su justicia liberadora. Dios de los trabajadores y los empobrecidos que son los sujetos protagonistas de su promoción, desarrollo y liberación integral (Lois, 2008); frente al mal e injusticia con sus ídolos del capital, del tener y de la riqueza-ser rico. Se nos manifiesta así toda una espiritualidad y cultura de la vida honrada en pobreza solidaria, en esa comunión de vida, de bienes y de luchas liberadoras por la paz y la justicia con los obreros, oprimidos y pobres de la tierra. En contra de la vida burguesa e individualista con la idolatría del poseer, del lujo y del derroche, del poder, del mercado y del dinero-riqueza que como falsos dioses corrompen todo, niegan la vida y al mismo Dios.

\section{La opción por los pobres siguiendo a Jesús}

Como hemos apuntado y nos transmite San Juan Pablo II, la Iglesia está vivamente comprometida en esta causa de la justicia social con los trabajadores y los pobres, porque la considera como "su misión, su servicio, como verificación de su fidelidad a Cristo, para poder ser verdaderamente la «lglesia de los pobres»)" (LE 8). Siguiendo a Jesús obrero, pobre y crucificado-resucitado, es la iglesia de los obreros, de los pobres y crucificados de la historia. La fe e iglesia de Jesús, que se entrega y compromete por la justicia liberadora e integral con los trabajadores y empobrecidos, para dar autentico testimonio del Evangelio.

Fe y espiritualidad que nos muestran la fraternidad universal, la solidaridad internacional y la justicia mundial con los obreros y empobrecidos del mundo, por encima de todo muro, barrera y frontera. En la actualidad, Francisco igualmente nos interpela a este compromiso moral y social con los otros, con las víctimas, los pobres y excluidos como sujetos de su promoción liberadora e integral (FT 18, 116). Aún más, la opción solidaria del amor preferencial por los pobres, categoría teológica central, es nuclear y esencial en la fe. "Para los cristianos, las palabras de Jesús tienen también otra dimensión trascendente; implican reconocer al mismo Cristo en cada hermano abandonado o excluido (cf. Mt 25,40.45). En realidad, la fe colma de motivaciones inauditas el reconocimiento del otro, porque quien cree puede llegar a reconocer que Dios ama a cada ser humano con un amor infinito y que «con ello le confiere una dignidad infinita». A esto se agrega que creemos que Cristo derramó su sangre por todos y cada uno, por lo cual nadie queda fuera de su amor universal. Y si vamos a la fuente última, que es la vida íntima de Dios, nos encontramos con una comunidad de tres Personas, origen y modelo perfecto de toda vida en común" (FT 85).

Tal como se observa, la tradición y enseñanza de la fe e iglesia nos transmite, de forma similar (unido inseparablemente) a la eucaristía, cómo el pobre es presencia (sacramento) real de Cristo pobre y 
excluido. Esta categoría teológica de la opción por los pobres, "enseñaba Benedicto XVI, «está implícita en la fe cristológica en aquel Dios que se ha hecho pobre por nosotros, para enriquecernos con su pobreza». Por eso quiero una Iglesia pobre para los pobres" (EG 198). Los pueblos, los trabajadores y los pobres como protagonistas de su promoción, desarrollo humano y ecología integral, de sus derechos y deberes (FT 117 118). Tal como nos comunican los Santos Padres y DSI, la auténtica solidaridad se realiza en la pobreza espiritual. Es decir, como remarca Francisco, siguiendo a Jesús es ser la iglesia pobre con los pobres (EG 198), en esa solidaridad compartida de la vida, de los bienes y el compromiso por la justicia con los trabajadores, con los empobrecidos de la tierra y las víctimas de la historia. En contra del pecado del egoísmo e idolatrías de la riqueza-ser rico, del tener, poder y la violencia (GonzálezCarvajal, 2009).

"Si alguien no tiene lo suficiente para vivir con dignidad se debe a que otro se lo está quedando. Lo resume san Juan Crisóstomo: «no compartir con los pobres los propios bienes es robarles y quitarles la vida. No son nuestros los bienes que tenemos, sino suyos»; o san Gregorio Magno, «cuando damos a los pobres las cosas indispensables no les damos nuestras cosas, sino que les devolvemos lo que es suyo»" (FT 119). Todo ello es el auténtico sentido, raíz e inspiración social de la realidad ética y espiritualidad del trabajo con este trascendental movimiento solidario, obrero y ese señalado día del $1^{\circ}$ de mayo. Frente a toda egolatría, corporativismo, populismo perverso o nacionalismos excluyentes e insolidarios, con la patria como ídolo, la fe e iglesia con el movimiento obrero sigue clamando: itrabajadores y parias (pobres) de la tierra uníos! Para ir concluyendo, queremos realzar así el recuerdo y la memoria que, en todo este nacimiento y desarrollo solidario del movimiento obrero, es imprescindible la aportación e inspiración de la fe, del cristianismo y el catolicismo (Pizarro, 1987; Díaz Salazar, 1998). Sin la cual, no se comprendería adecuadamente dicho movimiento solidario de los trabajadores y pobres.

Una fe cristiana-católica enraizada en sus renovadas congregaciones religiosas, con testimonios de la talla de Vicente de Paul, Alfonso M. de Ligorio o José de Calasanz y más tarde San Juan Bosco. Y, posteriormente, con testigos como el obispo Kettler y F. Ozanam, con Cardijn y su JOC, Mounier y el personalismo, S. Weil y L. Milani: M. Arboleya ya en España, con la HOAC de E. Merino, G. Rovirosa, T. Malagón o J. Gómez del Castillo (Díaz Salazar, 2001; Laboa, 2011). Como se ve, ellos son testigos de toda esta espiritualidad y ética del trabajo. Fueron pioneros de una verdadera opción liberadora por los pobres y los trabajadores, por los derechos sociales y las políticas públicas como son la educación, la sanidad, vivienda, los servicios sociales...; lo que hoy se conoce como el estado social de derecho-s.

\section{CONCLUSIONES}

Llegados al final de este estudio como nos transmite LE con la DSI, por tanto, vemos el sentido humanista, ético y espiritual del trabajo que está antes que el capital. La vida y dignidad de la persona trabajadora con sus derechos, como es un salario justo para el trabajador y su familia junto al destino universal de los bienes, tiene la prioridad sobre el beneficio, la ganancia y la propiedad. Un trabajo que se realiza en una empresa que debe ser una comunidad humana, con una economía social y cooperativa; en 
donde los trabajadores son los sujetos, dueños y gestores de la propiedad, de la marcha y el destino de la realidad empresarial, económica y social. Y es que al ser humano hay que ponerlo sobre el tener, la solidaridad y el compromiso por la justicia es lo primero, por encima de las cosas. Siguiendo a Jesús, Dios encarnado en el obrero de Nazaret, es esa existencia solidaria que comparte la vida, los bienes y la acción por la justicia con los pobres, con los trabajadores y las víctimas. Para irnos salvando y liberando del mal, del pecado y egoísmo con sus ídolos del poseer, de la riqueza-ser rico, del poder y la violencia.

Por todo ello, como realzan los obispos españoles en su significativa propuesta, La pastoral obrera de toda la iglesia (POTI), "la evangelización del mundo obrero, objetivo central de la pastoral obrera, es preocupación, responsabilidad y tarea de toda la Iglesia (EN 14; CLIM 19). Es ella, en cuanto cuerpo visible de la presencia de Cristo entre nosotros, quien recibe de Él la misión de «ir por el mundo entero predicando la Buena Noticia a toda la humanidad» (Mc. 15, 15-20). Fiel a la voluntad de su Señor, toda la Iglesia ha de sentirse y ha de mostrarse corresponsablemente unida, también en el testimonio cristiano, en el servicio evangélico a los trabajadores y también a la voluntad transformadora de eses condiciones sociales que tan directamente afectan al mundo obrero Por ello, es fundamental que en la comunidad creyente exista y se consolide una conciencia común, sinceramente compartida por todos los miembros del Pueblo de Dios, acerca de la necesidad, importancia y dimensiones fundamentales de una Pastoral Obrera verdaderamente eclesial" (POTI, II, introducción).

\section{REFERENCIAS BIBLIOGRÁFICAS}

Alburquerque, E. (2006). Moral social cristiana: camino de liberación y de justicia. San Pablo.

Alcaide, A. (2007). El trabajo, principio de vida. Edice.

Cortina, A. (2003). Construir confianza. Trotta.

Díaz Salazar, R. (1998). La izquierda y el cristianismo. Taurus

Díaz Salazar, R. (2001). Nuevo socialismo y cristianos de izquierda. HOAC.

Díaz Salazar, R. (2012). Pobreza, desigualdades y políticas de justicia. Las Palmas de GC. Universidad de Las Palmas de GC.

Franco, A. (2007). Marie-Dominique Chenu (Teólogos del siglo XX). San Pablo.

Gasda, E. (2012). Fe cristiana y sentido del trabajo. San Pablo.

Gasda, E. (2017). Cristianismo y economía: repensar el trabajo más allá del capitalismo. HOAC.

González-Carvajal, L. (2009). El clamor de los excluidos. Sal Terrae.

González-Carvajal, L. (2010). El hombre roto por los demonios de la economía. San Pablo.

Ibañez, H. (2002). De la integración a la exclusión. Sal Terrae.

Kerbo, H. (2003). Estratificación social $y$ desigualdad. McGraw-Hill. 
Labora, J. M. (2011). Por sus frutos los conoceréis: historia de la caridad en la iglesia. San Pablo

Lois, J. (2008). El Dios de los pobres. Secretariado Trinitario.

Peláez J. R, (2009). Del catolicismo social a la mística de la HOAC. D. Eugenio Merino Movilla (1881-1953), consiliario de la HOAC. Universidad Pontifica de Salamanca.

Pizarro, M. A. (1987). Lo cristiano y los cristianos en los orígenes del movimiento obrero. Voz de los sin voz.

Redorta, J. (2011). Hacia un mundo deseado: cambio social y conflicto. Milenio.

Rodríguez Guerra, J. (2013). Orden liberal y malestar social. Talasa.

Ruiz de la Peña, J. L. (2011). Imagen de Dios. Sal Terrae.
Ruiz de la Peña, J. L. (2012). Teología de la creación. Sal Terrae.

Sandoval, G. (2019). Las manos humanas son las Manos de Dios. Konrad-Adenauer-Stiftung e. V.

Segovia, J. L. (2013). El capital contra el trabajo. HOAC.

Sorge, B. (2017). Introducción a la doctrina social de la Iglesia. Sal Terrae.

Standing, G. (2013). El precariado, una nueva clase social. Pasado y presente.

Tornielli, A. y Galeazzi, G. (2015). Papa Francisco: esta economía mata. Palabra.

Fecha de recepción: 04/09/202 1 Fecha de aceptación: 27/09/2021 